\title{
As demandas emocionais na gestação e os seus desdobramentos no processo de parto
}

\author{
Emotional demands during pregnancy and its consequences in the delivery process \\ Exigencias emocionales durante el embarazo y sus consecuencias en el proceso del parto
}

Recebido: 05/07/2021 | Revisado: 14/07/2021 | Aceito: 21/07/2021 | Publicado: 27/07/2021

\author{
Nicole Gianni Teles da Silva \\ ORCID:https://orcid.org/0000-0002-6492-4048 \\ Universidade Estadual do Rio de Janeiro, Brasil \\ E-mail: enfnicoleteles@gmail.com \\ Marcele Zveiter \\ ORCID: https://orcid.org/0000-0001-6027-2276 \\ Universidade Estadual do Rio de Janeiro, Brasil \\ E-mail: marcelezveiter@ hotmail.com \\ Luciane Pereira de Almeida \\ ORCID: https://orcid.org/0000-0002-6463-9626 \\ Universidade Estadual do Rio de Janeiro, Brasil \\ E-mail: luciane.almeida.013@gmail.com \\ Ricardo Jose Oliveira Mouta \\ ORCID: https://orcid.org/0000-0002-1284-971X \\ Universidade Estadual do Rio de Janeiro, Brasil \\ E-mail: ricardomouta@ hotmail.com \\ Edymara Tatagiba Medina \\ ORCID:https://orcid.org/0000-0001-7180-6704 \\ Universidade Estadual do Rio de Janeiro, Brasil \\ E-mail: edymaramedina@gmail.com \\ Paula de Carvalho Pereira Pitombeira \\ ORCID: https://orcid.org/0000-0002-7316-0713 \\ Universidade Estácio de Sá, Brasil \\ E-mail: paulapitombeira.pp@gmail.com
}

\begin{abstract}
Resumo
Introdução: A gestação é considerada um momento transicional do mundo feminino, uma vez que implica mudanças fisiológicas, psicológicas e sociais na vida da mulher. Com a chegada do modelo tecnocrático na assistência obstétrica, os aspectos emocionais, humanos e culturais presentes nesse ciclo deixaram de ser considerados, subestimando o valor peculiar daassistência ao nascimento. Objetivos:Compreender os desdobramentos das demandas emocionais da gestação no processo de parto das mulheres atendidas na Casa de Parto David Capistrano Filho e compreender o contexto do atendimento às demandas emocionais das mulheres assistidas na Casa de Parto David Capistrano Filho. Metodologia: Trata-se de um estudo exploratório-descritivo de abordagem qualitativa documental. O estudo tem como cenário a Casa de Parto David Capistrano Filho situada no município do Rio de Janeiro. A técnica de coleta de dados consiste na análise de 24 prontuários de mulheres internadas na Casa de Parto David Capistrano Filho no ano de 2019. Resultados e Discussões: O estudo constatou que a gestação abrange demandas emocionais que podem ser ocasionadas ou agravadas por fatores externos como a falta de apoio familiar, traumas, luto, assim como o histórico pessoal de doenças psíquicas podendo ser identificadas através da singularidade do cuidado e a escuta ativa durantea assistência. Considerações Finais: As demandas são capazes de causar desequilíbrios emocionaisimportantes se não forem trabalhadas no pré-natal, podendo gerar o prolongamento do trabalho de parto e com isso aumentar a sensação de dor.
\end{abstract}

Palavras-chave: Emoções; Mulher; Parto; Enfermagem obstétrica; Cuidado pré-natal.

\begin{abstract}
Introduction: Pregnancy is considered a transitional moment in the female world, since it implies physiological, psychological and social changes in the woman's life. With the arrival of the technocratic model in obstetric care, the emotional, human and cultural aspects present in this cycle are no longer considered, underestimating the peculiar value of birth care. Objectives: To understand the consequences of the emotional demands of pregnancy in the delivery process of the women attended at the Casa de Parto David Capistrano Filho and to understand the context of meeting the emotional demands of the women assisted at the Casa de Parto David Capistrano Filho. Methodology: This is an exploratory-descriptive study with a qualitative documentary approach. The study is set in the David Capistrano Filho Birthing House located in the city of Rio de Janeiro. The data collection technique consists of
\end{abstract}


analyzing 24 medical records of women hospitalized at Casa de Parto David Capistrano Filho in 2019. Results and discussions:The study found that pregnancy covers emotional demands that can be caused or aggravated by external factors such as lack family support, traumas, mourning, as well as the personal history of mental illnesses, which can be identified through the singularity of care and active listening during care. Final considerations: Demands are capable of causing important emotional imbalances if they are not worked on during prenatal care, which can lead to prolonged labor and thereby increase the sensation of pain.

Keywords: Emotions; Women; I am leaving; Obstetric nursing; Prenatal care.

\section{Resumen}

Introducción: El embarazo se considera un momento de transición en el mundo femenino, ya que implica cambios fisiológicos, psicológicos y sociales en la vida de la mujer. Con la llegada del modelo tecnocrático en la atención obstétrica, se dejan de considerar los aspectos emocionales, humanos y culturales presentes en este ciclo, subestimando el valor peculiar del cuidado del parto. Objetivos: Comprender las consecuencias de las demandas emocionales del embarazo en el proceso de parto de las mujeres atendidas en la Casa de Parto David Capistrano Filho y comprender el contexto de satisfacción de las demandas emocionales de las mujeres atendidas en la Casa de Parto David Capistrano Filho. Metodología: Se trata de un estudio exploratorio-descriptivo con enfoque documental cualitativo. El estudio tiene como escenario la Casa de Parto David Capistrano Filho ubicada en el municipio de Río de Janeiro. La técnica de recolección de datos consiste en analizar 24 historias clínicas de mujeres hospitalizadas en la Casa de Parto David Capistrano Filho en 2019. Resultados y discusiones:El estudio encontró que el embarazo cubre demandas emocionales que pueden ser causadas o agravadas por factores externos como falta de apoyo familiar, traumas, duelo, así como el historial personal de enfermedades mentales, que se pueden identificar a través de la singularidad del cuidado y la escucha activa durante la asistencia. Consideraciones finales: Las demandas son capaces de provocar importantes desequilibrios emocionales si no se atienden durante la atención prenatal, lo que puede provocar un parto prolongado y por tanto aumentar la sensación de dolor.

Palabras clave: Emociones; Mujeres; Me voy; Enfermería obstétrica; Cuidado prenatal.

\section{Introdução}

Segundo Giaretta e Fagundez (2015), a gestação é considerada um momento transicional do mundo feminino, uma vez que implica mudanças fisiológicas, psicológicas e sociais na vida da mulher. Com a chegada do modelo tecnocrático na assistência obstétrica, os aspectos emocionais, humanos e culturais presentes nesse ciclo deixaram de ser considerados, esquecendo que a assistência ao nascimento se reveste de um caráter peculiar que vai além do processo de parir e nascer. (Ministério da Saúde, 2017)

A experiência vivida por uma mulher no trabalho de parto pode ser tanto positiva quantonegativa, deixando marcas inapagáveis em sua memória (BRASIL, 2017). Por estabelecer o encontro entre mãe e filho, este instante marca a passagem de um estado a outro, de forma irreversível, nesse momento a mulher desmistifica o bebê idealizado em prol do bebê real. Um parto com vivências positivas pode evitar frustrações que, poderão interceder na relação futura entre a mulher, o bebê, sua família e outras gestações. Dessa maneira, torna-se imprescindível conhecer as expectativas e desejos da parturiente para potencializar a qualidade da assistência. (Giaretta \& Fagundez, 2015)

A qualificação de atenção à gestante pela equipe de saúde, pode estabelecer umambiente favorável para a criação de vínculo. Esses profissionais devem acolher as mulheres de maneira singular, compartilhando com elas questões sobre o parto e frequentes. A valorização dos saberes, das escolhas e preferências da parturiente são relevantes dentro de umcontexto em que se almeja promover melhores resultados de saúde para o binômio. Rodrigues et al. (2017)

Os aspectos relacionados à humanização durante o parto, possuem ligação direta com a implementação da Rede Cegonha no SUS. Essa estratégia traz em seus objetivos boas práticas de atenção ao parto, nascimento, crescimento e desenvolvimento da criança até os 24 meses de idade. A inclusão de enfermeiras obstétricas ou obstetrizes no cenário da assistência ao parto normal de risco habitual, é essencialpara o avanço do movimento de humanização. Medeiros et al. (2016)

As enfermeiras com essa especialidade, possuem conhecimentos baseados em evidências e suas práticas são pautadas em tecnologias não invasivas de cuidados da Enfermagem Obstétrica. Dessa forma, evidencia-se que as mesmas, valorizam o 
cuidado centrado na mulher, respeitando suas subjetividades, preservando sua autonomia e a fisiologiado parto, com o objetivo de contribuir para empoderamento feminino durante todo esse processo. Medeiros et al. (2016)

Raramente uma mulher é indiferente sobre o seu parto. Durante esse momento, a maioria é envolvida por preocupações de ordem emocional oupsicológica. Tais preocupações abrangem o medo de alguma complicação com o feto ou de queele possa nascer morto, além do medo do seu próprio bem-estar. (Cavalcante, Oliveira, Ribeiro, \& Nery, 2007).

Desde a internação, a mulher passa um processo de ansiedade de intensidade variável, surgem questões significativas em sua mente, como a distância de seus filhos menores, quandoos têm, receio do profissional que irá assisti-la e como será o desfecho do trabalho departo. Somado a isso, esse evento pode representar para algumas uma hora bem-vinda, de uma espera prazerosa pelo seu bebê, outra o considera como um sacrifício e enquanto outra poderá percebê-lo como um sofrimento inigualável. (Cavalcante et al., 2007)

A gestação é um período inundado por fortes sentimentos que podem transbordar questões inconscientes maternas. Nota-se que essas questões emocionais apresentam grande variabilidade durante o parto, em alguns casos, tornam-se alarmantes pois podem influenciar a evolução do trabalho de parto e consequentemente a interação do binômio mãe e bebê. (Boas, Braga, \& Chatelard, 2007)

Baseada na situação acima apresentada formulou-se a seguinte questão norteadora: Quais são os desdobramentos das demandas emocionais na gestação no processode parto?

Desse modo, como objeto da presente pesquisa direciona às demandas emocionais na gestação e os seus desdobramentos no processo de parto. E com o propósito de atender a questãosupracitada, foram traçados os seguintes objetivos: Objetivo Geral - Compreender os desdobramentos das demandas emocionais da gestaçãono processo de parto das mulheres atendidas na Casa de Parto David Capistrano Filho. Objetivo Específico - Compreender o contexto do atendimento às demandas emocionais das mulheres assistidas na Casa de Parto David Capistrano Filho.

Diante do atual cenário obstétrico no Brasil, torna-se importante a existência de estudosque apresentem realidades e permitam o compartilhamento das emoções vivenciadas pelas parturientes. As questões emocionais durante a gravidez são consideradas fatores de risco paracomplicações obstétricas no trabalho de parto. Nesse sentido, esse estudo é relevante pois se somará aos esforços das produções científicas no campo dos cuidados da enfermagem obstétricabrasileira. (Wechsler, Reis, \& Ribeiro, 2016)

A realização deste estudo se justifica pelo fato de que na literatura nacional, existem poucas pesquisas que procuram abordar sobre o emocional das mulheres durante a construção do projeto de pesquisa que aqui se apresenta. Para comprovar tal afirmação, foi realizada uma busca online no mês de outubro de 2019, na base de dados da Biblioteca Virtual de Saúde (BVS), obtendo-se como resultado um total de 18 estudos encontrados. Destes, 14 estudos foram excluídos considerando: serem teses, dissertações ou trabalhos de conclusão de curso; serem artigos repetidos; serem artigos em língua estrangeira; não estarem disponíveis na íntegrapara consulta; o tema não se encaixar com a temática.

Após a busca e aplicação dos critérios de exclusão foram selecionados 3 (três) artigos científicos, utilizando a combinação dos seguintes descritores: sentimentos, mulher e parto. Segue abaixo o quadro com a caracterização dos estudos selecionados. 
Quadro 1 - Resultados da busca nas bases de dados e seleção de artigos pertinentes.

\begin{tabular}{|c|c|c|c|c|c|}
\hline CÓDIGO & TÍTULO & $\begin{array}{l}\text { ORIGEM } \\
\text { DOS } \\
\text { AUTORES } \\
\end{array}$ & OBJETIVOS & MÉTODOS & REVISTA/ANO \\
\hline Art.01 & $\begin{array}{l}\text { À margem da } \\
\text { humanização? } \\
\text { Experiências de parto } \\
\text { de usuárias de uma } \\
\text { maternidade pública } \\
\text { de Porto Alegre-RS } \\
\end{array}$ & $\begin{array}{l}\text { São } \\
\text { Leopoldo - } \\
\text { RS }\end{array}$ & $\begin{array}{l}\text { Analisar o cenário } \\
\text { obstétrico brasileiro. }\end{array}$ & $\begin{array}{l}\text { Estudo } \\
\text { qualitativo } \\
\text { exploratório }\end{array}$ & $\begin{array}{l}\text { Revista de Saúde } \\
\text { Coletiva, Rio de } \\
\text { Janeiro }\end{array}$ \\
\hline Art.02 & $\begin{array}{l}\text { Abordagem da equipe } \\
\text { de enfermagem acerca } \\
\text { do parto humanizado } \\
\text { no pré-natal: uma } \\
\text { revisão narrativa }\end{array}$ & Rio de Janeiro & $\begin{array}{l}\text { Identificar nas publicações } \\
\text { da literatura científica as } \\
\text { contribuições } \\
\text { desenvolvidas pela equipe } \\
\text { de enfermagem acerca das } \\
\text { abordagens quanto ao parto } \\
\text { humanizado durante as } \\
\text { consultas no pré-natal. }\end{array}$ & $\begin{array}{l}\text { Revisão } \\
\text { narrativa }\end{array}$ & $\begin{array}{l}\text { Revista dePesquisa } \\
\text { Cuidado é } \\
\text { fundamental }\end{array}$ \\
\hline Art.03 & $\begin{array}{l}\text { Percepção de } \\
\text { enfermeiros sobre a } \\
\text { humanização na } \\
\text { assistência de } \\
\text { Enfermagem no } \\
\text { puerpério imediato }\end{array}$ & $\begin{array}{l}\text { Rio Grande } \\
\text { do Norte - } \\
\text { RN }\end{array}$ & $\begin{array}{l}\text { Conhecer a percepção dos } \\
\text { enfermeiros sobre a } \\
\text { humanização na assistência } \\
\text { à puérpera, em um hospital } \\
\text { público da região do Seridó, } \\
\text { Rio Grande do Norte (RN) }\end{array}$ & $\begin{array}{l}\text { Pesquisa } \\
\text { exploratória e } \\
\text { descritiva, com } \\
\text { abordagem } \\
\text { qualitativa. }\end{array}$ & $\begin{array}{l}\text { Revista de } \\
\text { Pesquisa Cuidado } \\
\text { Fundamental }\end{array}$ \\
\hline
\end{tabular}

Fonte: Autores.

Considerando todo o exposto, este estudo pretende contribuir na compreensão dos aspectos emocionais inerentes à humanização da assistência prestada por enfermeiras obstétricas. Além disso, baseado nos elementos constitutivos dos registros de enfermagem, pode trazer à luz as percepções das Enfermeiras Obstétricas da Casa de Parto.

No campo do ensino, especificamente na especialização no modelo da Residência em Enfermagem Obstétrica, a contribuição pretendida é promover um olhar sensível aos desdobramentos e amplitude do cuidado profissional especializado, que se projeta para além dos protocolos assistenciais. No campo da pesquisa contribui para o conjunto de esforços empreendidos junto à linha de pesquisa Saberes, Política e Práticas em Saúde Coletiva e Enfermagem, no tema Formação em Enfermagem e Práticas de cuidado à Saúde.

\section{Metodologia}

Trata-se de uma pesquisa exploratória descritiva, com abordagem qualitativa documental. A pesquisa exploratória descritiva pode ser considerada a melhor escolha para pesquisar assuntos pouco abordados. Através desse método, torna-se possível identificar pontos de vista distintos de um determinado tema para adquirir uma visão geral sobre o assunto pesquisado, buscando descrever os aspectos encontrados. (Dyniewicz, 2014)

A pesquisa qualitativa é $m$ estudo que se preocupacom os aspectos da realidade que não podem ser quantificados, direcionando o estudo para o entendimento das relações sociais. (Gerhardt \& Silveira, 2009) Por sua vez, Minayo (2013) acrescenta que a pesquisa qualitativa trabalha com o lado subjetivo da realidade social através dos significados, causas, desejos, culturas, motivos, valores e atitudes dos indivíduos em uma sociedade. Dessa forma, nota-se que o estudo qualitativo corresponde ao espaço mais profundo das relações, e por esse motivo, torna-se a escolha ideal para abordar as emoções das parturientes.

A utilização de documentos em pesquisa traz riqueza de dados que podem ampliar a compressão de objetos importantes para apesquisa e Cellard (2008) afirma que a pesquisa documental possibilita adicionar a proporção do tempo o 
entendimento social, favorecendo a observação do processo de amadurecimento ou de evolução das pessoas, grupos, ideias, sapiências, comportamentos, intelectualidade, práticas,entre outros. (Silva, Almeida, \& Guindani, 2009)

O cenário desta pesquisa será na Casa de Parto David Capistrano Filho (CPDCF), localizada no município do Rio de Janeiro. A Casa de Parto é um Centro de Parto Normal (CPN), na modalidade de unidade isolada, e foi inaugurada em 08 de março de 2004. A equipe atual é composta por enfermeiras obstétricas, nutricionistas, assistentes sociais, auxiliares e técnicos de enfermagem, auxiliares de serviços gerais e motoristas de ambulância.

Para atender aos objetivos desta pesquisa, foram estabelecidos os seguintes critérios para as participantes do estudo: Critérios de inclusão: Mulheres que realizaram o acompanhamento do pré-natal na CPDCF e que foram internadas em trabalho de parto na CPDCF no ano de 2019. Critérios de exclusão: Mulheres que não foram internadas em trabalho de parto naCPDCF no ano de 2019 ou que não realizaram o pré-natal na CPDCF.

Foram coletados a partir de junho de 2020 dados de 24 prontuários referentes ao ano de 2019. A escolha dos prontuários foi realizada através de sorteio de números dos números de prontuários dos partos ocorridos em cada mês. Esse período foi escolhido por se tratar do tempo de concentração das atividades práticas nos cenários do parto e nascimento da especialização em Enfermagem Obstétrica na modalidade de Residência. A coleta de dados teve início após aprovação pelo Comitê de Ética em Pesquisa da Secretaria de Municipal de Saúde e Defesa Civil da Prefeitura do Rio de Janeiro (CEP SMSDC-RJ) e a Comissão de Ética em Pesquisa daUERJ (COEP). Aprovado no Parecer número: 4.026.837,

Após esta etapa foi realizado um contato telefônico com as mulheres cujos prontuáriosforam sorteados, com vistas ao esclarecimento sobre os objetivos da pesquisa, definições e compromisso acerca do anonimato na divulgação das informações pessoais e liberdade de participação ou não na pesquisa.

$\mathrm{Na}$ análise temática, utilizou-se uma das modalidades da análise de conteúdo. Dessa forma, através da análise de conteúdo espera-se obter a compreensãodo universo que cerca a demanda emocional da mulher em trabalho de parto, já que parte de uma leitura de primeiro plano dos registros nos prontuários, visando alcançar um nível mais profundo, buscou-se ultrapassar os sentidos que estão evidentes no material. Isso foi possível pela relação das estruturas semânticas (significantes) com as estruturas sociológicas (significados) dos enunciados dos textos com os fatores determinantes das suas características, sendo elas, variáveis psicossociais, contexto cultural e outras. (Minayo, 2014)

Uma das modalidades da análise de conteúdo é a análise temática e, para realizá-la é necessário achar os núcleos de sentido que compõem a comunicação. Esses núcleos ganham significado para o objeto que está sendo analisado, na medida das suas presenças ou frequências. Minayo (2014) recomenda uma sequência de três etapas operacionais para uma análise temática:

$1^{\circ}$ - Pré-análise: Escolha dos documentos; Leitura flutuante: impregnação pelo conteúdo; Constituição do corpus: validação qualitativa1; Formulação e reformulação dos objetivos: retomada da etapa exploratória, com correção de rumos, se necessário; Determinação da Unidade de registro (palavra-chave ou frase), da unidade de contexto(contexto de compreensão da unidade de registro), dos recortes, da forma de categorização, da modalidade de codificação, e dos conceitos teóricos gerais queorientarão a análise.

$2^{\circ}$ - Exploração do material: Busca das categorias: expressões ou palavras significativas.

$3^{\circ}$ - Tratamento dos resultados obtidos e interpretação: Operações estatísticas simples (porcentagens) que permitem colocar em destaque asinformações alcançadas; Interpretações relacionadas com o quadro teórico inicial. 
O presente projeto de pesquisa foi desenvolvido durante o ano de 2019. O tema e os objetivos foram estabelecidos entre os meses maio e agosto. A revisão de literatura e introdução entre julho e agosto. No período de agosto a outubro, a metodologia foi escolhida e o projeto apresentado na Faculdade de Enfermagem da Universidade do Estado do Rio de Janeiro (UERJ), como uma das etapas do Curso de Especialização em Enfermagem Obstétrica na modalidade Residência, da UERJ e no mês de novembro o projeto foi submetido ao CEP.

Após a aprovação do Comitê de Ética em pesquisa, número do parecer: 4.026.837, os dados foram coletados no mês de junho e julho de 2020 e analisados no período de agosto à outubro. As categorias foram elaboradas entre os meses julho e outubro e o relatório da pesquisafoi desenvolvido em outubro. Por fim, no mês de novembro o relatório parcial foi construído e posteriormente, em dezembro o relatório final foi defendido.

Por se tratar de pesquisa em prontuários o presente estudo foi pautado na resolução 466/12, de 12 de dezembro de 2012, que diz respeito às pesquisas e testes que são realizadas com seres humanos, constituída por diretrizes e normas regulamentadoras com grande importância para o desenvolvimento da ciência e que cumpridas nos projetos de pesquisa. Essa resolução concretiza o direito humano de dignidade, preservação de sua integridade e garantia de sua autonomia durante a participação em pesquisas científicas. (MS, 2012)

\section{Resultados e Discussão}

Para entender as demandas emocionais presentes na gestação, faz-se necessário conhecer os atributos pessoais e a história obstétrica das mulheres participantes deste estudo. Acaracterização dessas mulheres envolveu fatores de ordem pessoal, como idade, raça/cor, escolaridade, profissão e atributos relacionados a sua história obstétrica, como paridade, anticoncepção, planejamento da gravidez e número de consultas no pré-natal.

O quadro a seguir apresenta a caracterização dos atributos pessoais das mulheres que participaram deste estudo, evidenciando similaridades e diferenças apresentadas entre elas 
Quadro 2 - Caracterização dos atributos pessoais das participantes.

\begin{tabular}{|c|c|c|c|c|c|}
\hline MULHER & IDADE & $\mathrm{RACA} / \mathrm{COR}$ & ESCOLARIDADE & SITUACุÄO CONJUGAL & PROFISSÄO \\
\hline P1 & 30 & Negra & Superior completo & Casada & Sem registro \\
\hline P2 & 25 & Negra & $\begin{array}{l}\text { Ensino médio } \\
\text { completo }\end{array}$ & Solteira & Auxiliar de turma \\
\hline P3 & 27 & Negra & Superior completo & Casada & $\begin{array}{l}\text { Professora de educação } \\
\text { fisica }\end{array}$ \\
\hline P4 & 26 & Negra & Superior incompleto & Solteira & Estudante de veterinária \\
\hline P5 & 30 & Negra & $\begin{array}{l}\text { Ensino médio } \\
\text { completo }\end{array}$ & Solteira & Autônoma \\
\hline P6 & 23 & Branca & Superior incompleto & União estável & Auxiliar administrativa \\
\hline P7 & 22 & Branca & Superior incompleto & Solteira & Estudante \\
\hline P8 & 23 & Negra & Superior completo & Casada & Enfermeira \\
\hline P9 & 28 & Negra & $\begin{array}{l}\text { Ensino médio } \\
\text { completo }\end{array}$ & Solteira & Técnica de enfermagem \\
\hline P10 & 24 & Branca & Superior completo & Casada & Do lar \\
\hline P11 & 32 & Negra & $\begin{array}{l}\text { Ensino médio } \\
\text { completo }\end{array}$ & Casada & Do lar \\
\hline P12 & 18 & Negra & $\begin{array}{c}\text { Ensino médio } \\
\text { completo }\end{array}$ & Solteira & Manicure \\
\hline P13 & 28 & Negra & $\begin{array}{l}\text { Ensino médio } \\
\text { completo }\end{array}$ & Casada & Técnica de enfermagem \\
\hline P14 & 27 & Branca & $\begin{array}{l}\text { Ensino médio } \\
\text { completo }\end{array}$ & Casada & Professora \\
\hline P15 & 22 & Branca & $\begin{array}{l}\text { Ensino médio } \\
\text { completo }\end{array}$ & Casada & Auxiliar administrativo \\
\hline P16 & 22 & Negra & $\begin{array}{l}\text { Ensino médio } \\
\text { completo }\end{array}$ & Casada & Professora de dança \\
\hline P17 & 30 & Branca & $\begin{array}{c}\text { Ensino médio } \\
\text { completo }\end{array}$ & Casada & Sem registro \\
\hline P18 & 27 & Negra & $\begin{array}{l}\text { Ensino médio } \\
\text { completo }\end{array}$ & Divorciada & Técnica de estética \\
\hline P19 & 29 & Negra & Superior incompleto & Casada & Modelista \\
\hline P20 & 19 & Branca & Médio completo & Solteira & Recepcionista \\
\hline P21 & 31 & Branca & Superior completo & Casada & Farmacêutica \\
\hline P22 & 23 & Branca & Superior incompleto & Solteira & Técnica de enfermagem \\
\hline P23 & 23 & Negra & $\begin{array}{l}\text { Ensino médio } \\
\text { completo }\end{array}$ & Solteira & Cozinheira \\
\hline P24 & 20 & Branca & $\begin{array}{c}\text { Ensino médio } \\
\text { comoleto }\end{array}$ & Solteira & Manicure \\
\hline
\end{tabular}

Fonte: Autores.

Das 24 participantes do estudo, a maioria das mulheres se autodeclarou negra $(58,3 \%)$,dentre essas participantes, a maior parte não cursou o ensino superior, o que diferencia quando comparada às mulheres autodeclaradas brancas no estudo, em que a maioria teve acesso ao ensino superior.

O contexto histórico de marginalização vivenciado pela população negra no Brasil pode ser analisada através dos indicadores de desigualdade racial, que demonstram como pessoas negras, quando comparadas às brancas, têmmenos acesso à unidades de infraestrutura e habitação, escolaridade inferior e que estão inseridos no mercado de trabalho em ocupações de menor prestígio e menos salários. Tais vulnerabilidades geram exclusão e preconceito, podendo serem vistas como determinantes sociais de saúde. (Theophilo, Rattner, \& Pereira, 2018)

Além disso, constatou-se que as participantes eram em sua maioria casadas (50\%), em uma faixa etária entre 18 a 32 anos, com ensino médio completo (58.3\%). De acordo com Rocha, Barbosa e Lima (2017), um aspecto considerado positivo, é a presença de um parceiro fixo durante a gestação, por esse incentivar a realização do pré-natal, além de acompanhar as consultas, o que favorece a continuidade da assistência e seguimento das orientações prestadas. Rosa, Silveira, \& Costa (2014) afirmam que mulheres solteiras, sem parceiro algum, tendem a um pré-natal insuficiente.

As desigualdades socioeconômicas e culturais podem influenciar diferentes padrões defecundidade no Brasil. Esperase uma concentração dos nascimentos em torno de uma faixa etária cada vez mais velha, embora ainda se encontrem altos índices de fecundidade entre as adolescentes. Frente ao cenário de organização social e transição demográfica no Brasil, a 
percepção de desigualdades é um aspecto necessário para o monitoramento e avaliação das políticas de atenção à saúde das mulheres. (Fernandes, Santos, \& Barbosa, 2018)

A grande maioria das mulheres partem do pressuposto de que o momento ideal para exercer a maternidade é quando há a realização de fatores financeiros, profissionais e emocionais em suas vidas, levando a crer que após os 30 anos é o momento em que possuem mais maturidade e estabilidade para engravidar. Entretanto, de acordo com o quadro abaixo, por ser observado que a maior parte das participantes do estudo, não planejou a gestação, percebe-se que a maioria das mulheres tinha menos de 30 anos. (Aldrighi, Wall, Souza, \& Cancela, 2016)

O quadro abaixo retrata a informações importantes sobre a história obstétrica.

Quadro 3 - Caracterização dos atributos relacionados a história obstétrica.

\begin{tabular}{|c|c|c|c|c|}
\hline MULHER & PARIDADE & ANTICONCEPC̣̃O & GRAVIDEZ PLANEJADA & $\begin{array}{l}\text { NÚMERO DE } \\
\text { CONSULTAS }\end{array}$ \\
\hline Pl & G: II /PI / A0 & Não & Não & 06 \\
\hline P2 & G: I P 0 A 0 & Não & Não & 07 \\
\hline P3 & G: I P 0 A 0 & Não & Não & 06 \\
\hline P4 & G: I P 0 A 0 & Sim & Não & 09 \\
\hline P5 & G: I P 0 A 0 & Não & Não & 06 \\
\hline P6 & G: I P 0 A 0 & Não & Não & 08 \\
\hline P7 & G: I P 0 A 0 & Não & Não & 07 \\
\hline P8 & G: I P 0 A 0 & Não & Sim & 07 \\
\hline P9 & G: II /PI / A0 & Sem registro & Não & 09 \\
\hline $\mathbf{P} 10$ & G: I P 0 A 0 & $\operatorname{Sim}$ & Não & 05 \\
\hline P11 & G II P 0 A I & Não & Sim & 08 \\
\hline P12 & G: I P 0 A 0 & Não & Não & 05 \\
\hline P13 & G: I P 0 A 0 & Não & $\mathrm{Sim}$ & 08 \\
\hline P14 & G: I P 0 A 0 & Não & Sim & 08 \\
\hline Pl5 & G: I P 0 A 0 & Não & Não & 10 \\
\hline P16 & G III P I A I & Não & Não & 08 \\
\hline P17 & G II P I A I & Não & Sim & 09 \\
\hline P18 & G: I P 0 A 0 & Não & Não & 04 \\
\hline P19 & G: I P 0 A 0 & Não & Sim & 08 \\
\hline P20 & G: I P 0 A 0 & $\operatorname{Sim}$ & Não & 08 \\
\hline P21 & G: I P O A 0 & Não & Não & 07 \\
\hline P22 & G: I P 0 A 0 & $\operatorname{Sim}$ & Não & 08 \\
\hline P23 & G: I P O A 0 & Não & Não & 09 \\
\hline P24 & G: I P 0 A 0 & $\operatorname{Sim}$ & Não & 10 \\
\hline
\end{tabular}

Fonte: Autores.

No que se refere ao perfil gestacional e obstétrico, observou-se que $(79,1 \%)$ dasgestantes encontravam-se na primeira gestação, sem perda gestacional anterior. A maioria (75

\%) não realizava anticoncepção, entretanto (75\%) das mulheres também não planejaram a gestação.

As mulheres que possuem condições socioeconômicas desfavoráveis e desconhecem seus direitos sobre a reprodução, a contracepção apresenta-se como uma problemática. Dessa maneira, a gestação não planejada ocorre pela escassez de informações e dificuldade de acesso aos métodos contraceptivos, a utilização inadequada deles, a irregularidade na oferta do contraceptivo pela unidade, a disponibilização limitada dos diferentes métodos e efeitos adversos que influenciam ao abandono e ao limite de eficácia. (Coelho, Andrade, Vitoriano, \& Souza, 2012)

Outra questão refere-se ao número de consultas de pré-natal realizados na Casa de PartoDavid Capistrano Filho, em que a maioria $(87,5 \%)$ realizou no mínimo 6 (seis) consultas. Valeressaltar, que a CPDCF preconiza a realização do pré- 
natal paralelo na clínica da família ou na rede privada, assim como a realização das consultas de pré-natal na Casa, como condição paraparir na unidade.

A assistência à saúde deve assegurar a cobertura de toda a população-alvo da área de abrangência do serviço de saúde, garantindo minimamente 6 (seis) consultas de pré-natal e continuidade no atendimento, no acompanhamento e na avaliação do impacto destas condutas sobre a saúde materna e perinatal.Sendo assim, entende-se que a exigência do modelo da CPDCF justifica que a maior parte delastenham, no mínimo, seis consultas de pré-natal. (Ministério da Saúde, 2012)

Percebe-se que as participantes que realizaram menos de 6 consultas (12.5\%) na Casa, não planejaram a gestação. A gestação não planejada representa um dos grandes desafios no campo da saúde sexual e reprodutiva na atenção primária. (Evangelista, Barbieri, \& Silva, 2015) A gravidez não planejada ocasiona uma baixa adesão das mulheres nas unidades de saúde, além de ser considerada um fator de risco para o desenvolvimento da depressão pós-parto. (Almeida \& Arrais, 2016)

De forma a analisar as demandas emocionais na gestação e os seus desdobramentos no processo de parto, a construção das categorias de análise aconteceu da seguinte forma: foram enumeradas 1273 unidades de registro, as quais foram agrupadas em 6 unidades de significação. As unidades de significação foram agrupadas por afinidade de ideias e conteúdo, de modo que se destacaram 3 categorias centrais: "Rede de apoio durante a gestação", "Demandas emocionais das mulheres durante a gestação e o Trabalho de parto" e "Atendimento da enfermagem obstétrica frente as demandas emocionais das mulheres." A categoria 1 abrigou as unidades de significação intituladas: "Com o apoio de familiares e parceiros" e "Sem o apoio dos familiares e parceiros". A categoria 2 abordou as unidades de significação: "Sentimentos negativos" e "Sentimentos positivos". A categoria 3 se referiu as unidades de significação: "Tecnologias não invasivas de cuidado de enfermagem obstétrica" e "Condutas de enfermagempara apoio emocional".

O quadro a seguir sinaliza as unidades de significação observadas ao longo da pesquisa.

Quadro 4 - Unidades de significação.

\begin{tabular}{|c|c|c|c|c|c|c|}
\hline & \multicolumn{6}{|c|}{ UNIDADE DE SIGNIFICAÇÃO } \\
\hline & $\begin{array}{c}\text { Com o apoio de } \\
\text { familiares e } \\
\text { parceiros }\end{array}$ & $\begin{array}{c}\text { Sem o apoio de } \\
\text { familiares e } \\
\text { parceiros }\end{array}$ & Sentimentos negativos & Sentimentos positivos & $\begin{array}{c}\text { Tecnologias não } \\
\text { invasivas de cuidado } \\
\text { de enfermagem } \\
\text { obstétrica }\end{array}$ & $\begin{array}{l}\text { Condutas de } \\
\text { enfermagem para } \\
\text { apoio emocional }\end{array}$ \\
\hline P1 & 15 & 0 & 5 & 8 & 5 & 10 \\
\hline $\mathrm{p}_{2}$ & 6 & 11 & 2 & 9 & 3 & 6 \\
\hline p3 & 10 & 1 & 3 & 9 & 8 & 8 \\
\hline p4 & 4 & 9 & 11 & 14 & 8 & 12 \\
\hline P5 & 8 & 2 & 4 & 11 & 4 & 5 \\
\hline P6 & 19 & 3 & 22 & 13 & 4 & 16 \\
\hline $\mathrm{p} 7$ & 18 & 0 & 4 & 13 & 10 & 13 \\
\hline P8 & 14 & 0 & 3 & 18 & 4 & 6 \\
\hline $\mathrm{pg}$ & 15 & 0 & 09 & 12 & 3 & 9 \\
\hline P10 & 3 & 6 & 8 & 7 & 6 & 4 \\
\hline P11 & 11 & 8 & 12 & 19 & 7 & 8 \\
\hline P12 & 3 & 6 & 4 & 10 & 6 & 5 \\
\hline P13 & 16 & 2 & 19 & 15 & 9 & 20 \\
\hline P14 & 23 & 0 & 3 & 16 & 5 & 8 \\
\hline P15 & 21 & 3 & 6 & 30 & 6 & 13 \\
\hline P16 & 5 & 5 & 2 & 10 & 5 & 10 \\
\hline P17 & 3 & 9 & 15 & 15 & 4 & 6 \\
\hline P18 & 9 & 2 & 5 & 8 & 7 & 4 \\
\hline P19 & 6 & 5 & 4 & 17 & 5 & 4 \\
\hline P20 & 19 & 0 & 8 & 18 & 5 & 4 \\
\hline P21 & 13 & 4 & 4 & 12 & 5 & 9 \\
\hline P22 & 9 & 6 & 14 & 26 & 7 & 17 \\
\hline P23 & 17 & 4 & 5 & 22 & 7 & 9 \\
\hline P24 & 19 & 5 & 8 & 25 & 8 & 12 \\
\hline $\mathrm{N}^{\circ} \mathrm{UR}$ & 286 & 91 & 180 & 357 & 141 & 218 \\
\hline$\%$ UR & 22.47 & 7.15 & 14.14 & 28.04 & 11.08 & 17.12 \\
\hline CATEGORIA & \multicolumn{2}{|c|}{ Rede de apoio durante a gestação } & \multicolumn{2}{|c|}{$\begin{array}{l}\text { Demandas emocionais das mulheres durante a } \\
\text { gestação e o trabalho de parto }\end{array}$} & \multicolumn{2}{|c|}{$\begin{array}{l}\text { Atendimento da enfermagem obstétrica frente } \\
\text { as demandas emocionais das mulheres }\end{array}$} \\
\hline
\end{tabular}

Fonte: Autores. 


\section{Categoria I - Rede de apoio durante a gestação}

As ligações familiares têm a capacidade de influenciar o modo que as mulheresvivenciam o período de gestação, parto e pós-parto. A família tende a tornar-se a principal redede apoio durante essa fase, sendo considerado como um fator de risco ou de proteção no puerpério. (Melo, Angelo, Pontes, \& Brito, 2015) Literaturas apontam que, quando indica um fator de risco, a estrutura familiar pode contribuir para o desenvolvimento de depressão pós-parto, dificuldadesna amamentação, do vínculo mãe - bebê, dentre outros aspectos. (Romagnolo, Costa, Souza, Somera, \& Gomes, 2017)

A maternidade estabelece uma reorganização da estrutura familiar oriundas do nascimento de um bebê. As mulheres precisam de uma rede de apoio social, que representa a disponibilidade de pessoas significativas para proporcionarem suporte ao enfrentamento das diferentes circunstâncias que possam causar estresse durante o processo de transição. (Almeida \& Arrais, 2016)

Muitas pessoas podem exercer essa função, colaborando para o bem-estar dos envolvidos: parentes, os amigos, colegas de trabalho, vizinhos e até mesmo a equipe de saúde que a acompanhada. (Pio \& Capel, 2015) Dessa maneira, as formas de apoio social predominantes podem ser destacadas em apoio instrumental, relacionado ao auxílio financeiro, contribuição para a divisão das responsabilidades, orientações acerca da gravidez e apoio emocional,relacionado ao zelo com o outro. (Almeida \& Arrais, 2016)

Vale ressaltar, que o pré-natal pode estabelecer a interação entre o profissional, a gestante e sua família, contribuindo para que a gestante mantenha o vínculo com a unidade de saúde, reduzindo consideravelmente os riscos à saúde materno fetal. No estudo foi identificadoque a maioria das gestantes contaram com o apoio positivo de seus familiares e parceiros durante a gravidez, como a aceitação da gravidez, o acompanhamento das consultas de pré- natal e o suporte emocional oferecido por eles. Como pode ser constatado no registro da enfermeira no prontuário P14:

"Compareceu acompanhada do seu esposo e da sua mãe. Todos felizes com a gestaçãoe ansiosos com a chegada do bebê. Foi orientada sobre a questão de ficar tranquila, relaxar e pensar coisas boas agora no fim da gestação. Sua família está lhe mandando positividades neste momento, e parabenizo a atitude deles. Explico que esse vínculo familiar é importante para que P14 se tranquilize." (P14)

Durante a gestação, o companheiro(a) e a mãe da mulher representam, geralmente, as principais fontes de apoio dessa fase. As figuras femininas presentes nesse momento, na maioria das vezes, são mulheres com vivências da maternidade, que a nova mãe possui um bomrelacionamento, de forma que se sinta amparada para compartilhar dúvidas e anseios.

Em relação ao apoio prestado pela mãe das gestantes, pode ser considerado um ponto positivo para sanar as inseguranças das transformações desse ciclo. Sendo assim, o apoio de mulheres experientes no âmbito materno pode contribuir significativamente para o desenvolvimento das capacidades maternas da gestante, tornando-a mais segura e confiante. (Almeida \& Arrais, 2016)

$\mathrm{Na}$ pesquisa, tais aspectos foram identificados através de registros referentes a boa relação conjugal e familiar, estabelecimento de vínculo entre mãe, bebê e família, a presença da família simpática, comunicativa e participativa durante as consultas de pré-natal, como podeser visualizado nos prontuários 14 e 20:

"P14 veio a consulta sozinha, simpática e comunicativa. Conta que está vivendo um período movimentado por ter mudado para sua casa, está feliz pois está próximo de sua mãe.” (P14) 
"P20 compareceu a unidade acompanhada do namorado. A gestante demorou um pouco a aceitar a gestação, segundo ela, mas hoje (após ter ouvido o BCF do feto) e sua mãe estar receptiva a esta gestação, aceitou e possui uma forte rede de apoio." (P20)

Em contrapartida, a unidade de significação definida como falta de apoio de familiarese parceiros, identificou que a menor parte das participantes do estudo não tiveram o apoio adequado de seus familiares, como a não aceitação da gravidez pelo companheiro ou família ea presença de conflitos familiares.

A ausência de apoio familiar pode fragilizar e desencadear demandas emocionais relacionadas ao abandono. A gestante pode internalizar sentimentos de raiva, culpa, arrependimento, tristeza e até mesmo deixar de realizar o pré-natal. (Rocha, Barbosa, \& Lima, 2017)

Esse fato é constatado por diversas pesquisas, onde em média 50\% das mulheres que não possuem rede de apoio, tendem a abandonar o acompanhamento do pré-natal (BRAGA, et al., 2014). Observamos estes fatores nos registros dos prontuários 02 e 24 :

"P2 veio sozinha a Casa. Ela conta que o pai voltou a beber e que é agressivo, houveconfusão em casa com agressão entre seu irmão e outro parente na tentativa de contero pai. Ela se afastou emocionalmente dele e tem como "se virar" indo para a casa do namorado. Caso aconteça de novo está com acompanhamento de uma psicóloga." (P2)

"P24 compareceu a consulta acompanhada do seu companheiro. Demonstraraminstabilidade no relacionamento. D. que já é pai afirma que o casal combinou que nãoengravidariam este ano. P24 relata ter engravidado acidentalmente e seu companheiroacredita que foi proposital. Gestante não possui relacionamento harmonioso com suafamília, diz se sentir sozinha e podendo apenas contar com seu parceiro." (P24)

O apoio paterno durante o período gravídico vai além do suporte financeiro, podendo ser visto o envolvimento ativo do mesmo com a gravidez, acompanhando as consultas de pré- natal, as oficinas destinadas as gestantes, oferecendo apoio emocional, auxiliando com o planejamento do parto ou a escolha do nome do filho, disposto a participar do trabalho de parto dando todo suporte à parturiente. Embora gestar e parir sejam atividades exclusivas do corpo feminino, o homem, ocupando sua posição enquanto parceiro e pai, também é receptor das alterações gravídicas vivenciadas pela mãe de seu filho. (Melo et al., 2015)

Como citado anteriormente, a relação conjugal instável e a falta do envolvimento familiar durante a gestação podem ocasionar alterações emocionais importantes, além diminuiro vínculo da gestante com o serviço de saúde. No prontuário 11 , pode-se notar a dificuldade que o marido tem em desenvolver sua função paterna:

"Além disso, refere que seu esposo é uma pessoa bem impaciente e que para ele, as oficinas da Casa são consideradas perdas de tempo. Desse modo, P11 alega não desejar a presença do marido durante o trabalho de parto. Hoje durante a consulta eleestava na casa e preferiu não entrar na consulta de pré-natal." (P11)

"Conta que mora sozinha, mas é bem acolhida pela família do namorado e que apesarde estarem juntos, ele ainda não demonstrou tanto vínculo com o bebê se comparadoà ela. Está preocupada com a questão de trancar a faculdade e com o fato de seu namorado se mudar para outro país a qualquer momento. Relata que gostaria que eleparticipasse mais da gestação, e que apesar dele não demonstrar muito vínculo ele sepreocupa com ela." (P4) 
O reconhecimento dessas profissionais no país ainda é restrito, pois a institucionalização do parto afastou o caráter íntimo e privado de parir, naturalizando o parto hospitalar, de forma que escolher parir fora do hospital passou a ser considerado um evento anormal. Nesse sentido, evidenciou no estudo que muitos familiares são resistentes ao nascimento com enfermeiras obstétricas sem a presença médica:

"Veio para a casa com sua mãe que está vindo pela 1 vez na consulta. Diz que foi aoHMMR que foi atendida pela classificação de risco mas como estava cheio, sozinha, preferiu não aguardar o atendimento médico e foi embora. Converso seriamente coma cliente sobre o comprometimento com seu PN e das orientações dadas pela equipe. Não veio a oficina de amamentação pois estava cansada. Informa que foi a CF para iniciar o PN mas que não recebeu visita dos agentes para certificar seu endereço para iniciar. Sua mãe é extremamente desconfiada, perguntou se a equipe de Enfermagemfazia "pacote" questiono a finalidade da pergunta. Diz que era para saber pois acho que a enfermagem faz de tudo. Outro questionamento foi se a CP só havia enfermeiro.Percebo a falta de vínculo entre cliente com o nosso pré-natal." (P10)

\section{Categoria II - Demandas emocionais das mulheres durante a gestação e o trabalho de parto}

A Organização Mundial de Saúde (OMS), idealiza uma sociedade em que todas as mulheres e recém-nascidos tenham acesso a uma assistência de qualidade durante a gestação, parto e período pós-natal. Os cuidados pré-natais são considerados uma oportunidade de comunicação e apoio entre os profissionais, as gestantes, as famílias e à comunidade, em fasescríticas da vida das mulheres. A OMS destaca a importância de os cuidados pré-natais incluíremabordagens sobre as questões fisiológicas, socioculturais, emocionais e psicológicas da gravidez para a promoção de um cuidado respeitoso e efetivo. (MS, 2016).

Nesta categoria emergiram questões sobre as emoções das participantes, fragmentadas em negativas e positivas. Através do estudo, foi possível identificar que a maioria das participantes relataram e demonstraram para as enfermeiras, durante o pré-natal, a ocorrência de sentimentos positivos como a aceitação da gravidez, felicidade, desejo pelo parto normal e prazer. Essa afirmação pode ser observada nos prontuários 08 e 13:

"P8 é casada há 3 anos e interrompeu o uso do anticoncepcional para engravidar. Todos ficaram felizes ao descobrir a gestação. Conta que conheceu a Casa de Parto através de seu estágio na graduação de Enfermagem e gostou muito e sempre desejouparto normal. Refere vida sexual ativa e prazerosa." (P8)

"A gestação foi desejada por ela, o marido também queria, mas gostaria de ter deixadopara o final desse ano quando ele terminasse a faculdade. Ela diz que por fazer uso deanticoncepcional há 10 anos, achou que se interrompesse, o efeito perduraria, porém, assim que ela suspendeu o uso logo engravidou, e mesmo assim teve boa aceitação dela, do marido e da família." (P13)

Além disso, nesta categoria foram incluídos registros que mencionaram a satisfação dasgestantes com o pré-natal da CPDCF como a animação das mulheres em conseguir realizar o pré-natal na instituição, e em alguns casos há registros a respeito da insatisfação com aqualidade do pré-natal paralelo em outra unidade de saúde:

"P6 diz estar muito feliz em poder participar do pré-natal da Casa a tempo. Faz pré- natal paralelo porém ficou assustada pois o profissional não media o fundo uterino e não auscultava o BCF." (P6) 
"P12 compareceu a sua primeira consulta de pré-natal desacompanhada, muito simpática, comunicativa. Explico sobre a filosofia da Casa. Refere que gostou muito do acolhimento e que ela e sua mãe estão muito animadas com o pré-natal da Casa." (P12)

Desse modo, percebe-se a importância do acolhimento e da qualidade do atendimento prestado pelos profissionais de saúde na adesão das mulheres ao pré-natal. A criação de vínculopossibilita que as gestantes se sintam seguras e confortáveis para expressar suas emoções durante todo o acompanhamento da gravidez. De acordo com Zveiter e Souza (2015), é a partirda vivência das mulheres que as enfermeiras obstétricas da CPDCF realizam uma assistência singular. A significação do cuidado ultrapassa as barreiras do que é técnico abrangendo o melhor do lado humano.

Em contrapartida, muitas mulheres que não planejaram a gestação reagiramnegativamente ao descobrirem a gravidez, sendo observados nos registros das enfermeiras sentimentos como desespero e tristeza. Nota-se através do prontuário 06, que o acompanhamento na CPDCF proporcionava segurança no enfretamento desse processo:

"Relata que entrou em desespero ao descobrir a gestação, pois achava que não poderiaengravidar por ter relação a muitos anos e nunca ter acontecido. Chorou muito no início, mas que aos poucos foi se adaptando, teve muito apoio do marido e família, que festejaram desde o início. Hoje se sente mais tranquila e que já ama muito a bebê.Diz que não gosta do período gestacional, pois se sente muito diferente e não se achacomo as outras mães. Que anseia muito pelo dia do parto e pela chegada do bebê. Relata que acha que tudo isso foi ocasionado pelo seu trabalho e não pela gestação emsi. Ofereço serviço de psicologia, porém diz que está se sentindo mais segura em poder ter o atendimento na CPDCF." (P06)

Como mencionado acima, historicamente, o parto era considerado um evento completamente natural no qual este ocorria no ambiente domiciliar. Porém, com a medicalização do parto, a sociedade passou a considerar o nascimento seguro sendo apenas dentro do ambiente hospitalizar. No prontuário P11 é possível perceber essa tendência cultural, onde a parturiente, em um momento de fragilidade, associou segurança a sua transferência paraa maternidade de referência da CPDCF.

“Após cliente vomitar e manifestar vontade de evacuar, opto por reavaliá-la. Renata fala sobre a possiblidade de ir para o hospital. Explico a cliente sobre as fases do trabalho de parto e sobre a transferência, que se for a decisão dela que iremos realizar.Porém cliente opta por continuar na Casa.” (P11)

Na pesquisa o medo foi relacionado principalmente a traumas, a violência obstétrica, aomedo de não conseguir parir, da mudança ocasionada pelo nascimento do bebê, como podemosvisualizar nos prontuários 05 e 11:

"Disse que deseja muito um parto humanizado, pois seu primeiro parto foi a fórceps, fizeram episiotomia e ela ficou traumatizada. Disse que a gravidez não foi planejada,porém bem aceita, pois eles queriam ter um bebê em 2020.” Relata estar com medo da dor do parto e que o primeiro doeu muito.” (P9)

"Encontro Renata na banheira, ansiosa, dizendo que não vai conseguir. Estava na companhia do marido. Oferecemos lanche, fruta, mas só aceitou água. Após adotar várias posições na banheira optou em ir para a banqueta.” (P11)

A violência obstétrica é considerada como uma invasão do corpo feminino pelos profissionais ou por indivíduos íntimos e desconhecidos, durante o trabalho de parto, parto e pós-parto, mediante a práticas desumanizadas, negligência na assistência, realização de condutas dolorosas ou constrangedoras, sem o consentimento da parturiente. Soma-se a isso, a 
ocorrência de violência verbal e psicológica o que implica em danos emocionais e no desenvolvimento de traumas relacionados ao parto. (Andrade, Silva, Diniz, \& Caminha, 2016)

A participante P9 além de mencionar o medo da dor do parto, de cesariana e de possuir um trauma devido violência obstétrica, expõe para a enfermeira a sua dificuldade em aceitar a gravidez por não ter sido planejada, o que a levou a um quadro de depressão, segundo a gestante:

"P5 conta que conheceu a Casa por uma pesquisa na internet, porque tem medo de cesariana e violência obstétrica. Não planejou a gestação e levou um susto ao saber, diz que teve depressão no início, mas que agora já aceitou a gestação." (P5)

É papel da enfermeira obstétrica orientar e explicar, desde o início do pré-natal, as tecnologias não invasivas de cuidado e os seus benefícios no parto para que esse evento seja vivenciado de forma humanizada e respeitosa. O desconhecimento do corpo feminino, do processo fisiológico do parto e a influência cultural da família, aumenta a chance da violência obstétrica. (Rodrigues, Alvez, Penna, Pereira, Branco, \& Souza, 2017)

Durante a análise de dados dos prontuários, a gravidez não planejada foi identificada como um fator de risco impactante para a ocorrência da depressão durante a gravidez. Sendo assim, é necessário que os profissionais envolvidos no cuidado das mulheres exerçam um olharatento durante o ciclo gravídico-puerperal, principalmente, para o grupo de risco para seu desenvolvimento. Nos prontuários 6 e 18, a gravidez não planejada também foi associada a quadros de tristeza, preocupação e isolamento social.

"A gestação não foi planejada, mas não estava usado nenhum método contraceptivo. Refere que quando contou a gravidez para o pai da criança ele sumiu e só agora retornou, mas não tem muito contato com ela e nem com sua gestação. Refere que nocomeço ficou muito mal com a notícia da gestação, ficou sem fome, sem comer e se isolou um pouco, mas que agora está bem com a notícia da gravidez." (P6)

"A gestação não foi planejada e P19 confessa que no início quando descobriu não estava tão feliz com a notícia. Mas que a maternidade está já mudando suas percepções, e já se mostra contente P18 se mostrou um pouco preocupada com as novidades que a gestação possa trazer.” (P18)

Outra questão refere-se a tristeza referente ao luto recente. De acordo com o Parkes e Prigerson (2013), o luto pode ser definido como um conjunto de alterações emocionais, físicas e comportamentais, incluindo a tristeza, ansiedade, solidão, desconfortos no estômago, aperto no peito, fadiga muscular, preocupação, insônia, perda do apetite e isolamento social que surgem como resposta à uma morte.

Para Marques, (2015) o luto possui uma grande semelhança com a depressão devido ossintomas em comum, incluindo tristeza, distúrbios do sono, apatia, sentimentos de desespero, cansaço físico e mental. Entretanto, segundo American Psychiatric Association (2014), é possível diferenciar o luto de um episódio depressivo através da constatação de que durante o luto, sentimentos de vazio e perda predominam, enquanto na depressão o humor deprimido é persistente gerando a incapacidade de antecipar a felicidade e o prazer.

É possível perceber através do prontuário 20 o quanto o falecimento de uma pessoa querida, principalmente um parente familiar, pode ocasionar alterações físicas e emocionais ao longo da gestação, o que representa um fator de risco importante para a ocorrência de um estresse emocional durante o trabalho de parto: 
"P20 veio a consulta de pré-natal acompanhada de A e sua amiga, estavam todos tristes devido o falecimento do irmão de P20 ontem. P20 diz ter passado mal durante a madrugada devido o ocorrido, apresentando náuseas e vômitos, mas que durante a manhã já estava melhor. Padrão de sono preservado, exceto nessa madrugada. Não realizo exame especular a pedido de P20, que estava bastante abalada." (P20)

O desequilíbrio emocional pode acontecer por outros fatores durante o trabalho de parto como pode ser visto no prontuário 02, a história pessoal da gestante envolvendo instabilidade no relacionamento com o pai do bebê e conflitos familiares causados por alcoolismo pelo seu pai, o que a afastou emocionalmente e fisicamente dele, segundo a mesma, pode ter influenciado o prolongamento do seu trabalho de parto. Durante esse período, mesmo com o uso de diversas tecnologias de cuidado como escalda pés e óleo ativador, a parturiente precisouser transferida para a maternidade de referência da CPDCF devido ruptura prematura das membranas ovulares há 18 horas.

A ansiedade é considerada uma "resposta fisiológica natural" que gera sintomas de taquicardia, medo, tensão e inquietação. Esses sintomas podem ser encontrados em outras patologias como fobias e síndrome do pânico. Na gravidez, a ansiedadetornou-se um sentimento comum devido à fase de vida vivenciado pela mulher, por ser um momento de fragilidade emocional, de alterações hormonais e modificações sociais que influenciam diretamente o estado emocional. (Prado, Kureabayashu, \& Silva, 2012) No que se refere ao estudo,é possível identificar os sinais da ansiedade devido a particularidades da gestação e a histórico clínico anterior:

"P15 veio a consulta com seu esposo, bem simpáticos e comunicativos. Refere ter passado bem o período entre as consultas. P15 se mostra bem ansiosa com a possibilidade de não parir na Casa. Faz muitas perguntas $e$ conversamos bastante sobre o assunto." (P15)

"P15 veio a Casa na companhia de seu marido referindo aumento da dor e perda do tampão mucoso. Observo que P15 está ansiosa, respirando ofegante." (P15)

"No decorrer da consulta, a P22 diz ter realizado tratamento com psicólogo para ansiedade no ano passado e afirma sentir o coração acelerar algumas vezes, mas commenor frequência." (P22)

\section{Categoria III - Atendimento da enfermagem obstétrica frente as demandas emocionais das mulheres}

Para a enfermagem obstétrica o cuidado transcende a prática assistencial através do ato de compartilhar e escutar, facilitando a expressão de sentimentos. A assistência prestada pelas enfermeiras obstétricas em Casas de Parto acontece de forma integral que começa na gravidezaté o puerpério estabelecendo um relacionamento de proximidade e confiança entre as profissionais e as gestantes. (Zveitter \& Souza, 2014) Assim, torna-se possível observar no estudoos resultados do atendimento as demandas emocionais das mulheres.

A enfermagem obstétrica considera o processo do parto como um fenômeno feminino sendo a mulher a única protagonista. O envolvimento dessas profissionais no parto fisiológicocontribui para a humanização da assistência por meio do respeito, da escuta ativa, da singularidade de cada mulher e da utilização de tecnologias não invasivas de cuidado pautado em evidências científicas. Nesse sentido, o enfoque humanista possui maior flexibilidade quando comparado a tecnomedicina em relação aos protocolos e rotinas institucionais, assim como outras particularidades de cuidado. (Silva et al., 2009)

Conforme visto durante o estudo, o pré-natal da CPDCF, além de ser um momento de rastreamento de alterações clínicas da gestação também é considerado um espaço para oferecer apoio emocional à gestante e a sua família, a fim de prepará-los para o processo de gerar, parire nascer. 
Nesse sentido, o estudo identificou que a mudança da dinâmica familiar com o nascimento de um bebê e a valorização da presença do acompanhante para o compartilhamento do cuidado frente as demandas da gestante são assuntos bastante abordados pelas enfermeiras obstétricas da Casa, seguidos de estratégias para sanar essas demandas como pode ser visto no prontuário P9, P6 e P16:

"Conversamos bastante sobre a relação de sua filha com o bebê. Sua filha rejeita o irmão. Após de muita conversa P9 se sente mais segura para conduzir a situação." (P9)

"Em relação à aceitação da gravidez pela filha de 9 anos ainda está difícil, mas está procurando estratégias para lidar com a situação. Convido a trazer a filha na próxima consulta como modo de criar afinidade com esse momento." (P9)

"P6 veio a consulta com sua mãe e companheiro, felizes, ansiosa pela chegada do bebê. Faço escuta ativa dos medos e ansiedades da família e tiro dúvidas, encorajando pensamentos positivos. Sugiro atividades de lazer lúdicas, que favoreçam liberação de hormônios." (P6).

"Conversamos sobre a mudança na dinâmica familiar com a chegada do bebê e ela demonstrou muita preocupação em relação ao cuidado com os 2 filhos e com as tarefas do lar. Estímulo o comparecimento do parceiro nos grupos e consultas para oestabelecimento de vínculo com a Casa e para sanar possíveis dúvidas. " (P16)

Como condição para realizar o pré-natal na Casa, as mulheres se comprometem a participar dos grupos educativos oferecidos gratuitamente. As oficinas temáticas têm como objetivo favorecer trocas de experiência e de conhecimento entre os profissionais, à gestante e a família, abordando desde as primeiras mudanças físicas e hormonais até o puerpério, sendo marcadas conforme a idade gestacional de cada mulher para que elas consigam vivenciá-las nomomento certo e que tenham contato com gestantes que estejam passando pela mesma fase.

O "Chá do parto" é o último grupo do período gravídico, que desperta e trabalha intensamente as emoções das gestantes através da despedida da barriga, com a presença de seus familiares. A gestante P04, participava do Chá do Parto quando começou a contrair, ao ser avaliada após a oficina, foi constatado que ela estava em fase ativa do trabalho de parto.

Como citado anteriormente, P4 apresentou muitas demandas emocionais negativas durante a gestação, relacionadas a solidão, por não possuir uma forte rede de apoio e pela possiblidade do seu parceiro ir embora para outro país, antes do nascimento do bebê. Conclui-se que esse evento somado a presença do seu companheiro, pode ter proporcionado um momento de relaxamento e consequentemente a liberação de ocitocina para o início das contrações:

"P4 está mais feliz, pois o esposo que irá viajar a trabalho não vai mais no próximo mês, portanto poderá acompanhar o nascimento do bebê. Estão juntos organizando a mudança da família posteriormente.”(P4)

No estudo, notou-se que a maioria das mulheres comparecia frequentemente às oficinas educativas: modificações, vínculo, grupo de nutrição, gênero e sexualidade, amamentação, parto e tecnologias, trabalho de parto, cuidados com o recémnascido e Chá do Parto. Porém, énotório a resistência ao processo fisiológico do parto e a persistência cultural de um modelo intervencionista, da participante que não frequentou regularmente as oficinas da Casa: 
"P17 pergunta se não poderia ser isenta da participação das oficinas. Reforço que isso não será possível devido a filosofia da Casa e que ela se comprometeu a participar para se manter vinculada. P17 concordou e disse que virá participar."(P17)

"P17 não participou dos grupos de final, não valorizou. Ao ser liberada referiu desejode realizar uma cesariana, pois seria mais fácil parir. Cliente sem perfil para a Casa. Liberada com orientação.” (P17)

"P17 encontra-se muito incomodada, refere dores mais intensas. Oriento respiração devagar, porém, P17 tem dificuldade para seguir orientações, refere que está muito difícil e solicita avaliação/toque. Converso sobre a possibilidade de avaliação ter se mantido, porém casal insiste em ser avaliado. Oriento respiração, banho morno, posições confortáveis. P17 prefere ficar em decúbito dorsal na cama com esposo.” (P17)

Uma das estratégias para promover o protagonismo e autonomia da mulher durante o processo de nascimento do seu filho é a utilização do Plano Individual de Parto. Durante a consulta de enfermagem, o profissional enfermeiro deve orientar e informar os direitos das mulheres apresentando o plano de parto como uma ferramenta de comunicação em ummomento de fragilidade. É importante esse documento abordar sobre o manejo da dor, formas de conforto, as preferências da mulher antes e depois do parto e reflexões sobre suas crenças. Aragon et al. (2013)

Vale ressaltar, que nos casos de anormalidades durante o ciclo gravídico puerperal, as mulheres são transferidas para a maternidade de referência da CPDCF, tornando ainda mais relevante a construção do plano de parto para a extensão da cobertura da humanização. Para Narchi et al., (2019) as gestantes que realizam seu plano de parto e apresentam na entrada da maternidade possuem um melhor atendimento dos seus desejos e expectativas através da sensibilização dos profissionais de saúde que as assistem. Durante as consultas de pré-natal daCasa é possível perceber o quanto as enfermeiras valorizam a confecção do plano de parto:

"P4 relata não ter conseguido confeccionar o plano de parto, digo para que ela encare a confecção como um momento de maior internalização do momento do nascimento e percepção das suas expectativas." (P4)

"P6 compareceu a consulta de pré-natal acompanhada da sua mãe e companheiro. Está muito ansiosa com a chegada de G. Tem medo de parir no hospital. Conversamos durante muito tempo sobre seus medos e receios, a cliente chorou e após acolhê-la oriento que tirasse essa fase final para fazer coisas que tragam prazer." (P6)

"P7 veio a consulta de pré-natal acompanhada com seu parceiro M. Ambos receptivose atentos as orientações que foram dadas acerca das dúvidas. A perguntar a cliente sobre queixas, verbalizou que está um pouco ansiosa. Conversamos a respeito da confecção de seu plano de parto, onde relatou que fará. Conversamos sobre atividadesque lhe dê satisfação e seja prazerosa." (P7)

Destaca-se no estudo que a maior parte das gestantes realizam o plano de parto, externalizando as suas vontades. Dessa maneira, percebe-se que essa particularidade do cuidado é mais forma de a enfermagem obstétrica atender as demandas emocionais das mulheres, favorecendo a aproximação de ambas, como visto em trechos dos planos de parto anexados nos prontuários:

“Nós, mãe e pai da S., estamos muito contentes de contar com o apoio da equipe destamaternidade no nascimento da nossa bebê. Sabemos que o curso do trabalho de partopode tomar diferentes rumos. No entanto, em condições ideais 
gostaríamos de seguiro seguinte plano de parto e sempre que o plano não puder ser cumprido gostaríamosde ser previamente informados e consultados a respeito das alternativas." (P7) "Quero que tudo ocorra com bastante naturalidade, alerta para toda equipe dasenfermeiras da Casa para um parto de respeito... luz baixa e ambiente, e se possível quando Miguel sair eu esteja na banqueta. Que Deus me ajude nesse momento. E toda ajuda das enfermeiras estão bem vindas." (P13)

"Agradeço muito a equipe envolvida a ajuda para tornar esse momento tão importantepara nós em um momento feliz e tranquilo como deve ser." (P19)

"P22 aqui expresso total desejo pelo parto natural e peço que haja transferência apenasem caso de risco para minha filha e para mim, mas sempre avisando e consultando- me sobre qualquer mudança desse plano." (P22)

Nesse contexto, o compartilhamento de decisões entre as enfermeiras obstétricas e as parturientes, frente a intervenções necessárias durante o trabalho de parto, também foi constatado nos registros, como visualizado no prontuário 04:

"No trabalho de parto foi utilizado aromaterapia não especificada, respiração, massagem, penumbra, banho, para promover o relaxamento de P14. Após avaliação foi perguntada a parturiente se aceitaria ocitocina, após dúvida, houve um espaço paraa parturiente conversar com a família. Ela conversou e aceitou. " (P4)

A possibilidade de transferência para a unidade hospitalar, em alguns casos, era considerada um fator negativo devido ao medo desse ambiente. Após identificar essa questão as profissionais trabalhavam o lado emocional das gestantes de acordo com a sua particularidade. Desse modo, a identificação do medo hospitalar durante o acompanhamento gestacional é de extrema importância para diminuir o risco de estresse emocional caso haja a necessidade de transferência dessas mulheres:

"Veio a Casa com seu marido e sua mãe, com relato de lombalgia intensa, dor em baixo ventre e contrações. Foi diagnosticada na unidade de referência com infecção do trato urinário. Cliente muito nervosa, agitada, com medo de retornar ao Mariska. Falando várias coisas ao mesmo tempo como internação, indução, entre outros. Converso sobre o medo e ansiedade fazendo que seu corpo responda de forma negativa. Opto em examinar pois a cliente chegou desesperada falando que estava saindo." (P6)

"P6 compareceu a consulta de pré-natal acompanhada da sua mãe e companheiro. Está muito ansiosa com a chegada de G. Tem medo de parir no hospital. Conversamos durante muito tempo sobre seus medos e receios, a cliente chorou e após acolhê-la oriento que tirasse essa fase final para fazer coisas que tragam prazer." (P6)

Observa-se que as gestantes ao comparecem a uma consulta de intercorrência, mesmo não estando em trabalho de parto ativo, são avaliadas integralmente pelas enfermeiras obstétricas e caso necessitem de um suporte emocional as profissionais compartilham a possibilidade de permanecerem em observação na suíte, disponibilizando as tecnologias não invasivas de cuidado, até sentirem segurança para retornarem as suas casas.

Percebe-se que nos prontuários 6 e 22 as gestantes procuraram a unidade algumas vezesmotivadas intrinsicamente pela insegurança com o momento do parto. Considerando a escuta ativa como fonte de expansão do cuidado, as enfermeiras obstétricas propiciam um momento de conversa sobre os medos e anseios da gestante: 
"Veio a consulta relatando aumento das contrações desde ontem. Converso sobre faselatente, ansiedades e medos do período e faço escuta ativa de P6. Sugiro atividades relaxantes, lúdicas que ajudem nesse momento. Deixo Casa de Parto disponível para que retorne sempre que desejar. Percebo P6 ansiosa com a idade gestacional que se aproxima de 41 s." (P6)

P6 veio a unidade com a mãe e marido muito ansiosa informando que o bebê estava muito quieto, observou saída do tampão mucoso rosado e odor em absorvente de moderada intensidade. Ao chegar, p6 estava muito chorosa, ao auscultar batimento cardíaco fetal: 166/170 bpm, ofereci lavanda, repouso na penumbra em decúbito lateral esquerdo, após 40 minutos P6 estava mais calma." (P6)

"P22 vem a casa com familiares queixando-se de incremento das contrações. Conversei muito sobre as fases do trabalho de parto, as contrações de forma lúdica, usando bonecos e bacia de pano. Sugiro atividades habituais do dia a dia, converso com os acompanhantes para que sejam sujeitos de apoio emocional nesse momento."(P22)

As Tecnologias Não invasivas de Cuidado de Enfermagem Obstétrica (TNICEO) consistem em conhecimentos estruturados, desenvolvidos e usados pelas enfermeiras obstétricas para disponibilizar outras formas perspectivas de cuidado às parturientes. Essas profissionais assumem o lugar de coadjuvantes para que o destaque seja o empoderamento feminino. (Vargens, Silva, \& Progianti, 2018)

Todos os prontuários citaram TNCEO utilizadas durante o processo de parto, tais comopenumbra, música, escalda pés, massagem, aromaterapia, banho, banheira, ambiente acolhedor, deambulação e respiração. Sendo a aromaterapia e a água morna, as tecnologias não invasivasregistradas no atendimento as demandas emocionais das gestantes.

"P7 veio a unidade acompanhada do Marido e da Doula referindo contrações frequentes. P7 conta que há várias noites, não dorme. Ofereço lavanda. Às $22 \mathrm{~h}, \mathrm{P7}$ sente-se melhor, orientada quanto ao trabalho de parto vinda a unidade quando julgarnecessário." (P7)

"P22 está no chuveiro. Afirma que dor nas costas aliviou com água morna." (P22)

"P24 segue em observação, mantendo-se na banheira com água morna relatando que é onde se sente melhor. Vocalizando durante as contrações e mantendo-se tranquila assim com seu acompanhante. Permanecem em ambiente tranquilo, com penumbra. Ofereço óleo essencial de lavanda para uso aromático.” (P24)

Entende-se que a aromaterapia neste contexto se baseia na aplicação terapêutica de Óleos Essenciais (OE). São compostos orgânicos de origem vegetal, que podem ser extraídos de partes da planta, podendo ser absorvidos através da inalação, uso tópico na pele ou por ingestão com o objetivo de proporcionar o bem-estar físico e psicológico. (Silva et al., 2009)

É evidente na pesquisa que a utilização de óleos essenciais promove o bem-estar das parturientes, registrados pelas enfermeiras da CPDCF como óleo acelerador, óleo ativador, óleorelaxante e óleo de lavanda. Após o uso desses aromas, em sua maioria, foi observado mudançano comportamento das gestantes, proporcionando "tranquilidade".

O OE de lavanda é bastante utilizado durante otrabalho de parto por possuir em sua fórmula propriedades calmantes, relaxantes, antiestresse e estimulantes. Na análise de dados, constatou-se que o óleo essencial de lavanda além de causar "tranquilidade" após o uso, também proporcionou "segurança" "concentração" e "calma", segundo os registros dos prontuários 24 e 23. (Hoare \& Wilson, 2010) 
Além disso, nos prontuários 12 e 23, também foi registrado melhora na dinâmica uterinae dilatação após a tranquilidade causada pelo uso da aromaterapia. Vale ressaltar, que os óleos essenciais utilizados na CPDCF, em sua maioria, não são especificados no prontuário. Dessa forma, o não aprofundamento dessa temática é considerado uma limitação do estudo.

\section{Considerações Finais}

Fortemente motivado pelas experiências acadêmicas e o desejo de aprofundamento nos estudos relacionados com a saúde mental das mulheres, o presente estudo teve como foco as demandas emocionais na gestação e os seus desdobramentos no processo de parto. Além disso, o cenário onde se desenvolveu a pesquisa, a Casa de Parto David Capistrano Filho, foi um campo de práticas decisivo na formação da enfermeira que realizou a investigação que aqui se apresenta. Percebeu-se ao final da escrita deste relatório de pesquisa que o seu planejamento ea sua execução transcenderam a formalidade de cumprimento de mais uma etapa necessária para obtenção do título de especialista em enfermagem obstétrica. Houve aquisição de conhecimento específico e desejo de saber mais, constituindo-se numa abertura de novos planos acadêmicos e motivação para seguir estudando e investigando.

A metodologia usada mostrou-se eficaz para que o objetivo geral de compreender os desdobramentos das demandas emocionais da gestação no processo de parto das mulheres atendidas na Casa de Parto David Capistrano Filho, e o objetivo específica de compreender o contexto do atendimento às demandas emocionais das mulheres assistidas na Casa de Parto David Capistrano Filho, fossem alcançados.

Desde a exploração bibliográfica inicial foi possível entender que a gravidez é um momento de grande transformação na vida das mulheres. No que tange as demandas emocionais na gestação e os seus desdobramentos no processo de parto, os resultados trouxeram a presençaou e a ausência de uma rede de apoio formada por familiares e os parceiros durante a gestação; as demandas emocionais das mulheres durante a gestação e o Trabalho de parto, manifestadas como sentimentos negativos e sentimentos positivos; e o atendimento da enfermagem obstétricafrente as demandas emocionais das mulheres, expresso como tecnologias não invasivas de cuidado de enfermagem obstétrica e como condutas de enfermagem para apoio emocional. Neste estudo ficou claro que a gestação abrange demandas emocionais que podem ser ocasionadas ou agravadas por fatores externos como a falta de apoio familiar, traumas, luto, assim como o histórico pessoal de doenças psíquicas e o fato da gravidez não ter sido planejada,podendo ser identificadas através da singularidade do cuidado e a escuta ativa durante a assistência.

Ao final desta investigação foi entendido que as demandas emocionais são capazes de causar desiquilíbrios emocionais importantes se não forem trabalhadas no pré-natal, podendo gerar o prolongamento do trabalho de parto e com isso aumentar a sensação de dor. Em contrapartida, sentimentos positivos no final da gestação como o prazer e relaxamento podem favorecer o início do trabalho de parto, assim como a sua evolução. Ressalta-se a necessidade do desenvolvimento de estudos voltados para a construção de um novo conceito que esclareçaessas evidências.

O cuidado pré-natal da Casa de Parto David Capistrano Filho, oferecido pelas enfermeiras obstétricas, consegue identificar as fragilidades emocionais da gestação e oferecersuporte para atendê-las, através de conversas, oficinas e utilização das tecnologias não invasivas de enfermagem obstétrica, contribuindo significativamente para qualidade da assistência. $\mathrm{O}$ cuidado de enfermagem obstétrica no pré-natal que funcionou como pano de fundo do presente estudo, deve ser replicado e difundido com vistas ao atendimento das demandas emocionais das gestantes dentro do escopo de uma assistência integral à saúde.

A partir das pesquisas realizadas para a construção deste estudo, os autores notaram a necessidade de elaborar outras buscas sobre a temática e área envolvidas em questão, aprofundando-se cada vez mais devido a escassez de material existente. Desta maneira, acreditamos que futuramente teremos outros projetos para apresentar e assim, colaborar com a pesquisa, as comunidades acadêmicas e principalmente com a sociedade. 


\section{Referências}

Aldrighi, J. D., Wall, M. L., Souza, S. R., \& Cancela, F. Z. (2016). As experiências das mulheres na gestação em idade materna avançada:revisão integrativa. Revista da Escola de Enfermagem, 50(3), 512-521.

Almeida, N. M., \& Arrais, A. R. (2016). O Pré-Natal Psicológico como Programa de Prevençãoà Depressão Pós-Parto. Psicol. cienc. prof., Brasília, 36(4), 847-863.

American Psychistric Association. (2014). Major Depressive Disorder and the "Bereavement Exclusion".

Andrade, P. O., Silva, J. Q., Diniz, C. M., \& Caminha, M. F. (2016). Fatores associados à violência obstétrica na assistência ao parto vaginal em uma maternidade de alta complexidade em Recife, Pernambuco. Revista Brasileirade Saúde Materno Infantil, 16(1), $29-37$.

Aragon, M., Chloa, E., Dayan, R., Kluftinger, A., Lohn, Z., \& Buhler, K. (2013). Perspetives of expectante women and health care providers on birth plans. Journal of Obstetrics and Gynaecology Canada, 35(11), 979-985.

Boas, L. M., Braga, M. C., \& Chatelard, D. S. (2013). Escuta Psicanalítica de Gestantes no Contexto Ambulatorial: Uma Experiência em Grupos de Fala. Universidade de Brasília Brasília, 44 (1), 8-15.

Cavalcante, F. N, Oliveira, L. V., Ribeiro, M. M., \& Nery, I. S. (2007). Sentimentos vivenciados for mulheres durante trabalho de parto e parto. Revista Baiana de Enfermagem, 21(1), 31-40.

Cellard, A. A. (2008). Pesquisa qualitativa: enfoques epistemológicos e metodológicos. Petrópolis, Vozes.

Coelho, E. A., Andrade, M. L., Vitoriano, L. V., \& Souza, J. J. (2012). Associação entre gravidez não planejada e o contexto socioeconômico de mulheres em área da Estratégia Saúde da Família. Acta paul. enfermagem, 25(3), 415-422.

Dyniewicz, A. M. (2014) Metodologia da pesquisa em saúde para iniciantes. Difusão Editora.

Evangelista, C. B., Barbieri, M., \& Silva, P. L. (2015). Gravidez não planejada e fatores associados à participação em programa de planejamento familiar. Revista de Pesquisa Cuidado é Fundamental Online, 7(2), 2464-2474.

Fernandes, F. C., Santos, E. G., Barbosa, I. R. (2019). A idade da primeira gestação no Brasil: Dados da pesquisa nacional de saúde. J. Hum. Growth Dev., 29(3), 304-312.

Gerhardt, T. E., \& Silveira, D. T. (2009). Métodos de pesquisa. Editora da UFRGS.

Giaretta, D. G., \& Fagundez, F. (2015). Aspectos psicológicos do puerpério: Uma revisão. Psicologia pt, 1-8.

Hoare, J., \& Wilson, S. (2010). Guia completo de aromaterapia: um curso estruturado para alcançar a excelência profissional. Pensamento.

Medeiros, R. M., Teixeira, R. C., Nicolini, A. B., Alvares, A. S., Corrêa, A. C., \& Martins, D. P. (2016). Cuidados humanizados: a inserção de enfermeiras obstétricas em um hospital de ensino. Rev. Bras. Enferm., 69 (6), 1091-1098.

Melo, R. M., Angelo, B. H., Pontes, C. M., \& Brito, R. S. (2015). Conhecimento de homens sobre o trabalho de parto e nascimento. Escola Anna Nery, Revista de Enfermagem, 19(3), 454-459.

Ministério da Sáude. (2012). Atenção ao pré-natal de baixo risco. Brasília, DF.

Ministério da Saúde. (2017). Diretrizes de Assistência ao Parto Normal.

Ministério da Saúde. (2016). Resolução nº 510, de 07 de abril de 2016, Conselho Nacional de Saúde

Minayo, M.C. (2013). O desafio do conhecimento: Pesquisa qualitativa em saúde. São Paulo: Hucitec.

Pio, D.A., \& Capel, S. M. (2015). Os significados do cuidado na gestação. Revista Psicologia e Saúde.

Prado, J. M., Kureabayashu, L. F., \& Silva, M. J. (2012). Eficácia da auriculoterapia na redução de ansiedade em estudantes de enfermagem. Rev Esc Enferm USP, 46(5), 1200-1206.

Rocha, S. I., Barbosa, S. V., \& Lima, S. A. (2017). Fatores que influenciam a não adesão ao programa de pré-natal. Revista Recien-Revista Científica de Enfermagem, 7(21), 21-29.

Rodrigues, F. A., Lira, S. V., Magalhães, P. H., Freitas, A. L., Mitros, V. M., \& Almeida, P. C. (2017). Violência obstétrica no processo de parturição em maternidades vinculadas à Rede Cegonha. Reprodução \& Climatério, 32(2), 78-84.

Romagnolo, A. N., Costa, A. O., Souza, N. L., Somera, V. C., \& Gomes, M. B. (2017). A família como fator de risco e de proteção na gestação, parto e pós-parto. Semina: Ciências Sociais e Humanas, 38 (2), 133-146.

Rosa, C. Q., Silveira, D. S., \& Costa, J. S. (2014). Fatores associados à não realização de pré-natal em município de grande porte. Revista de Saúde Pública, 977-984.

Silva, J. R., Almeida, C. D., \& Guindani, J. F. (2009). Pesquisa documental: pistas teóricas e metodológicas. Revista brasileira de história \& ciências sociais, $1(1)$. 
Research, Society and Development, v. 10, n. 9, e36810917884, 2021

(CC BY 4.0) | ISSN 2525-3409 | DOI: http://dx.doi.org/10.33448/rsd-v10i9.17884

Rodrigues, D. P., Alvez, V. H., Penna, L. H., Pereira, A. V., Branco, M. B., \& Souza, R. M. (2017). O descumprimento da lei do acompanhante como agravo á saúde obstétrica. Texto \& Cotento Enfermagem, 2-10.

Theophilo, R. L., Rattner, D., \& Pereira, E. L. (2018). Vulnerabilidade de mulheres negras na atenção ao pré-natal e ao parto no SUS: análise da pesquisa da Ouvidoria Ativa. Saúde Coletiva.

Vargens, O. M., Silva, A. C., \& Progianti, J. M. (2017). Contribuições de enfermeiras obstétricas para consolidação do parto humanizado em maternidades no Rio de Janeiro. Esc Anna Nery.

Wechsler, A. M., Reis, K. P., \& Ribeiro, B. D. (2016). Uma análise exploratória sobre fatores de risco para o ajustamento psicológico de gestantes. Psicologia Argumento, 34(86).

Zveitter, M., \& Souza, I. E. (2014). Solicitude constituindo o cuidado de enfermeiras obstétricas à mulher-que-dá-à-luz-na-casa-de-parto. Escola Anna Nery, 19(1), 86-92. 